
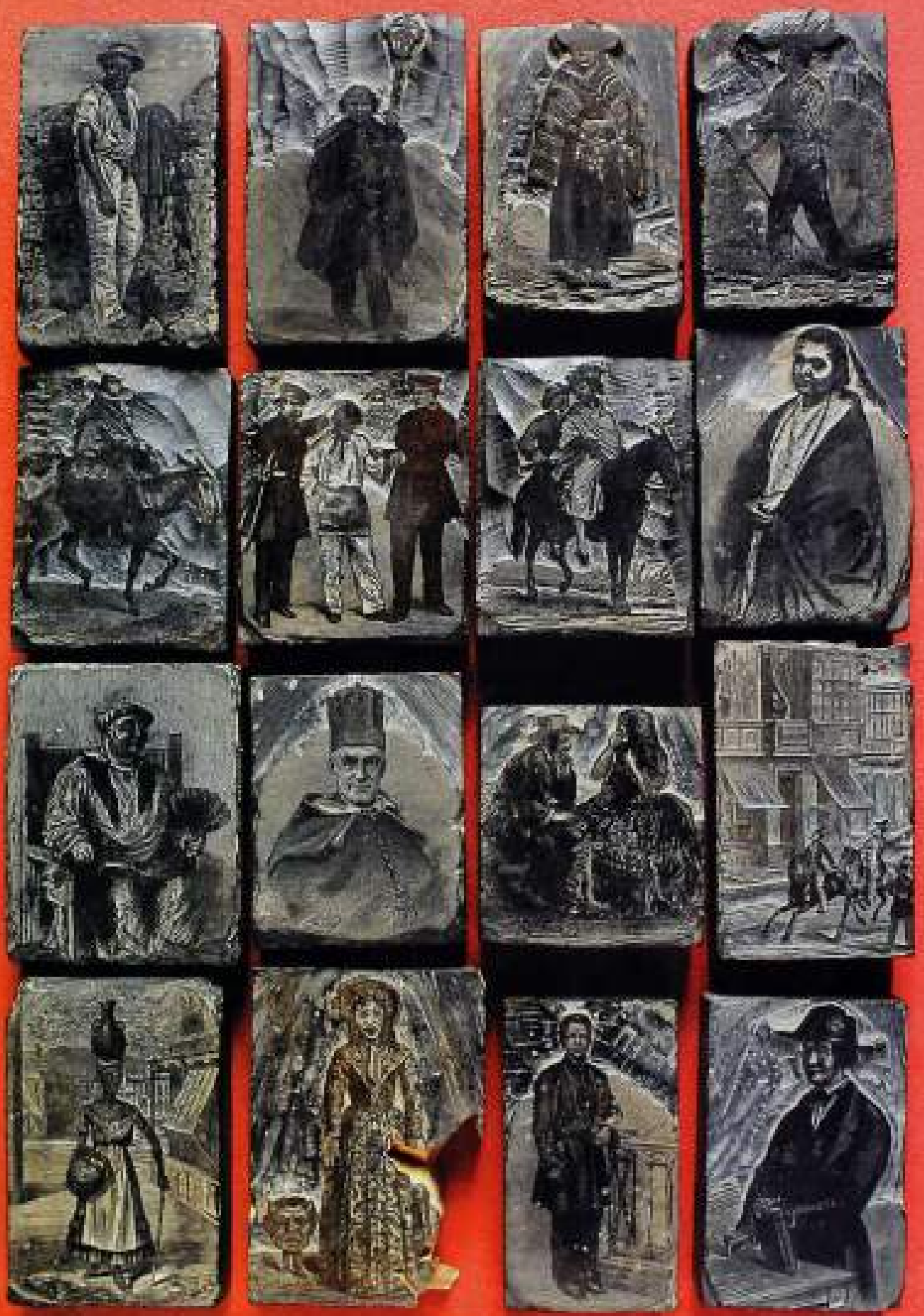


\section{Los tacos del Murciélago}

Herman Schwarz

Centro de la imágen

El periodismo ilustrado nace en la década de 1840 y fue la época de oro del grabado en madera. La litografía y la xilografía brillaron antes de que la fotografía llegase a las imprentas. El hallazgo de 29 bloques o tacos de madera originales usados para la impresión del memorable libro de Manuel Atanasio Fuentes, Lima, apuntes históricos, descriptivos, estadísticos y de costumbres, impreso en París en 1866, sirve para darle una nueva mirada al uso de la fotografía en el marco de la historia del periodismo ilustrado y de la imprenta en el Perú en la segunda mitad del siglo XIX.

\section{Tacos de madera / Manuel Atanasio Fuentes / Lima / Inicios de la Fotografía peruana / Eugene Maunoury / Courret Hermanos / Tarjetas de visita}

Pictorial journalism was born in the 1840's and was a golden era for printmaking. Lithography and woodprints glow before photography could get to the presses. The finding in Lima of 29 original Frenchwoodblocks used in the printing of the memorable book: Lima, or Sketches of the capital of Peru, historical, statistical written by Manuel Atanasio Fuentes and printed in Paris in 1866, brings up new ways to look the use of photography in the early days of Peruvian pictorial journalism and also helps to look deeper in the history of printmaking in Peru in the second half of the XIX century.

\section{Woodblocks / Manuel Atanasio Fuentes / Lima / Early Peruvian Photography / Eugene Maunoury / Courret Hermanos / Visit cards}

\section{El periodismo ilustrado / Siglo XIX}

Un hallazgo extraordinario nos trae de vuelta el libro memorable: Lima, apuntes históricos, descriptivos, estadísticos $y$ de costumbres de Manuel Atanasio Fuentes ${ }^{1}$ (MAF). Fue impreso en París en 1866 y el rasgo resaltante es su gran profusión de grabados, hechos a partir de fotografias de los estudios de Maunoury y Courret Hermanos de Lima. Las ilustraciones describen la vida cotidiana en la Ciudad de los Reyes a través de imágenes de paisajes urbanos y de tipos y costumbres, además de una galería de retratos de damas de la aristocrática sociedad limeña y de personajes políticos y eclesiásticos de la época.

Han sido "redescubiertos" veintinueve tacos de madera originales utilizados para la impresión de este libro, lo que representa un hecho sin precedentes. Se encuentran en buen estado de conservación a pesar de tener casi 150 años de antigüedad y haber trajinado desde que fueran burilados en Francia y atravesado el Atlántico para terminar pasando por diversas imprentas de Lima. Debemos añadir la rareza de este hallazgo ya que son desconocidas

1 Manuel Atanasio Fuentes. Lima, apuntes históricos, descriptivos, estadísticos y de costumbres. Librería de Firmin Didot hermanos, hijos y Co. París 1867. Colección Servais Thissen. 

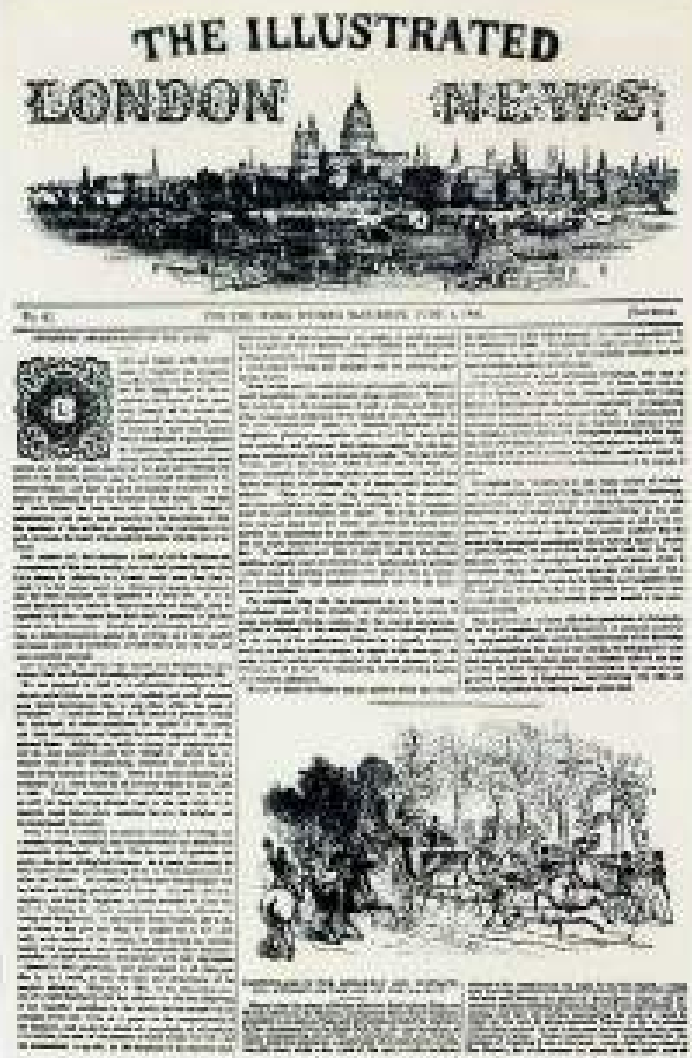

1รตัต 2 otras matrices xilograficas sobrevivientes, tan coumunes en los incios de la prensa ilustradda a mediados dat siglo XiX. Fig. 1

\section{Antecedentes / Pionerus de la prensa ilustrada}

En 1842, apenas tres ailos despues de la imenciant de la fotografia, apareció en Inglaterra el primer numero del semanario The ifiestrated London News; ers un inpresa de 16 páginas ilustrado con 32 grabados (xilografias), lo que constituyó el mayor atractive y la clave de ai popularidad El exito fue tan apoteosico que al ano siguiente su formato fue copiadx al milimetro por hos seinanarias CZlinstrativo de Paris $y$ el Die Iinsarierte de Leipzig. tendencia que se repitió en casi todas las.capitales de Europa y América. Fig, 2

Aungue stutne sorprendente, sus primeres reporteros grifices bo fueron fotografos sino dibujantes llamados "artistas especiales", La recién nacida fotografia no exa capaz de retratar la fugacidad de ua evento y aun era tecnologicamente imposible reproducirlas, por medios fotomecánicos, en la imprenta. Si Dien se pubjicaron libros con fotografias, estos eran amados con copias originales en calotipe y kas tirajes. por esa misma razon, eran de pocos ejemplares?

Efectivamente, las pntmeros reporteros capaces de captar la acción y el instante preciso, de dia o de mache, lueron los "artistas especiales". La labor de estos dibojantes era ibustrar la noticia: algumas veces desde el lugar de los heclsos, reconstruyendo los eventos basandose en la version de los testigos presenciales; otras veces con la ayuda de daguerrotipos, pin. turas 4 otros grabados, L.a rutina era mas o menos de esta manera; la ilustración (dibujo. daguerrotipo o grabador llegaba a la redaccion y esta era dibujada sobre la superficie de un bloque de madera especial, que en el case de los angleses era un firkish baxwoof del tamano exacto a como iba a aparecer impreso. Inmediatanente era burilado por un técnico grabador y emviado a los talleres, a la sección de los cajistas, y prepacado para la impresión.

In estos años iniciales del periodismo ilustrado la fotografia estaba asin en pañales. Fquipirs pesados, procesos qutimicos complicados, altameate toxicos y -sobretodo- de

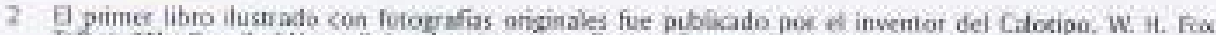

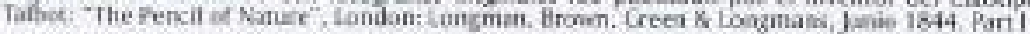

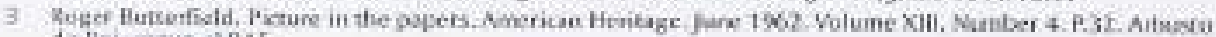
de Bol, wgun es RAE 
largas exposiciones. no peratitian registrar, pos eiemplo, a los transeuntes en una simple escena calleiera. Tuvieron que pasar caatro largas decadas para que lit fotografía - como tal- reemplazara a los yrabados kxilografía y a la litografial en su rol de lustrar los acontecimientos noticioscs de actualidad.

\section{La fotografia coano} testigo de la realidad

Antes de que el semana. no The Miustrated Landin News cumpliera un ano de vida, la fotogratia llego al periotico a participar en la dura competencia por "retratar la realidad". So le comisions al daguerrotipista M. Claudet fotografiar la cuelad de londres desde una plataforma constuuida, sobre la columna del Ducase de Yorik, a 40 metros de altura. El resul.

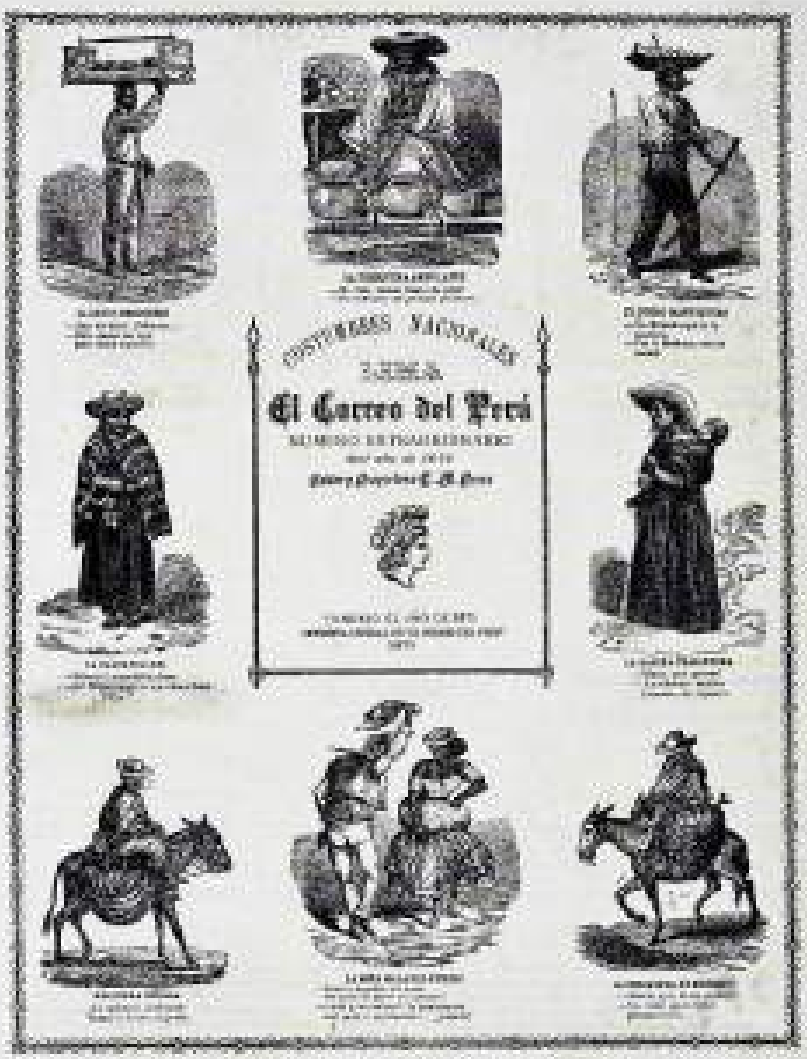

Reied 3 tado fue una lamina que media un metro y treinta centimetros de ancho por un metro de alto y fue publescla ef 7 de enero de 1843. Esta copia traia dos vistas de la ciudad desde la columas, una def norte y otra del sur. Este primer grabado, hecho a partir de daguerrotipos, fuc una empresa he roica y extraordinaria que jamis fue repetida en la historia de la prensa ingles. fotografio y dibujante iban registrando y construyendo por partes, como un gran rompecabezas, la imagen panoraimica de la-ciudad. Los bloques de madera que se utilizaben parn los gra. bados nomalmente no median mais de veinte centimetros de díanetro, por lo que hubo que imventas un sistega para las alustraciones mis grandes. Estas debian unirse a base de tornillos que sujetaban los segmentos de madera por la parte de arras se necesitaron sesenta piezas de madera de boy $y$ diecinueve grabadores para completar el trabajo en dos. meses, trabajando dia y roche.

A final la plancha de la panorsimica de Londres era tan grande y delícada que prefirieron no arriesgarla en la prensa a yapor ya que el calory ta humedad podian destruirfa: asi que tuvieron que hacer una glancha de metal -a partir del original de madera-para poder imprimirla, Toda inncwacion tecnológica conileva una serie de inventivas y con estas se de-

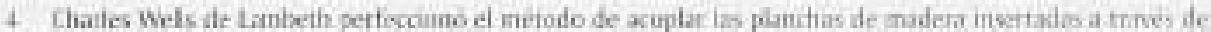

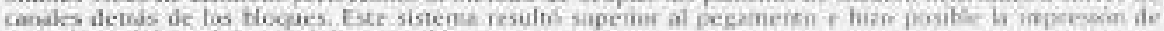

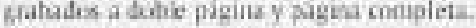


sarmollan nuevos procedimientos y técnicas para trabajar de forma ordenada y funcional. El publicar tal cantidad de ilustraciones en cada número se volvió tan cotidiano, qoe algunos grabadores se fueron especializando en retratos cr arquitecturat stros en abboles y follaje: y otros destaciban detalles de luces y sombras.

\section{La prensa ilustrada en el Peru | El Conto def Rerí |187|-1875|}

En 1839, el mismo año que se anunció el invento de Daguerre, apareció en Lima el diario E) Counerio. Su prumera ilustración litográlical periedistica y cientifica, se publico el 20 de setiembre del mismo ano. Eue la famosa imagen de "El hombre de la escalandra"s Sin em. bargo sus ilustraciones diarias fueron minimas y prácticamente limitadas a algunos avisos publicitarios, hasta el arribo de la técrica de la impresión de medis tono, capaz de reproducs una fotografia. Hablamos de la titima decada del siglo XIX.

La prensa ilustrada llegó recién con fil Comes det Seni, subtitulada "periódico semanal con ilustraciones mensuales", y fundado por los hermanos Manuel y Trinidad Perez el 16 de setiembre de 187 it:

La publicación del Correo del Peri, acometida en un pais que carece de artistas disenistas y gribadores, de los elementos necesanos para crearlos y aun de obreros tipografos, es una empresa que a cada paso tropezará con escolios que intenten detenerla en su camine: Ella no mirará estos ohstáculos sino los recursos con que cuenta para salvarlos. Ningùn mèrito tendria emprender lo que fuese facil abotdac Si: tsic| hasta de abrenos ripografos carece el pais. Esta es la amarga verdad. Ea manor parte no se ocupa del perfeccionamiento de su arte; al contrario, huye de las oficinas en que podria encontrarlos. El director mismo de esta empresa ha tenido que comar los tipos en la mano para acudir dignamente al llamamiento de la exposición. Ojalá alguna xez nuestros operarios entren con entusiasmo en el camino del estudio, ojals comprendan que los cipos son las mảs preciadas armas de la civilización. armas que houran a gaien Las maneji,

Así reza el quejumbroso editorial de los Pérez en el ntimero dedicado a la Primera Exposición Nacional de 1872 , realizada en el Parçae de ha Bxposicion en lo que se suponian las avances de la modema indastria peruana. Sin embargo y a pesar de poseer las más modermas instalaciones, las imprentas peruanas carecian de grabadores y tipografos. Los grabados eran hechos en Europa (Londres o Parisł y, una vez llegados a Hina, muchos eran, despues de usados, alquilidos a los diferentes medios para su reimpresión.

Es interesante por $e s 0$ mismo un aviso publicado al poco tiempo en el misno periodico:

Ch. Dissaux, Graveur Dessinateur, 30 Rue Camand (Pileta de Santo Domingol. Este artista recien Ilegado de Paris, dibuja y graba sobre madera Itustraciones, siendo su especialidad los diseños perfectos de sellos. medallas, piezas de arte y de joyeria'.

Prosto los hermanos Perez usarian a los grabadores recién llegados: L Dumont y J. Zabala, quienes hacian su trahajo con menos destrexa pero compensaban con un menor costo y

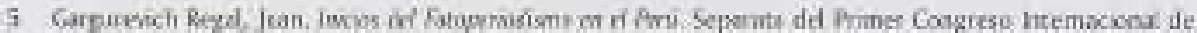

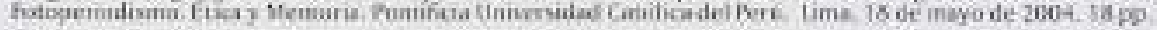

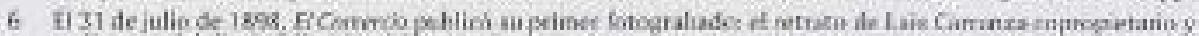
ocdioctor del diano fallecios el dia anterior

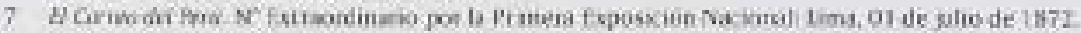

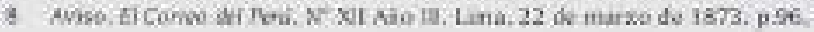


mayor rapidez, como bien dice el historiador Juan Gargurevich. Sin embargo utilizaron algunos de los tacos originales que MAF usó en su libro sobre Lima, sobre todo los referidos a las imágenes de tipos y costumbres. Fig. 3

\section{La Lima de Fuentes}

La primera vez que vi un ejemplar del libro de MAF fue en casa de Javier Sologuren, allá por el año ochentaiuno. En esa época Sologuren dirigía la revista cultural Cielo Abierto de Centromín (la minera estatal) y me contrató como fotógrafo. El poeta tenía en su biblioteca un ejemplar del libro de Lima de MAF y sus grabados fueron reproducidos en innumerables ocasiones para ilustrar notas evocativas sobre el pasado de nuestra ciudad. La revista de Centromin no fue la excepción y yo me encargaba de hacer las reproducciones.

El hecho de haber sido publicado en tres idiomas: primero en francés e inglés (1866) y al año siguiente en español, dice mucho del interés que existía en Europa acerca del Perú y su ca-

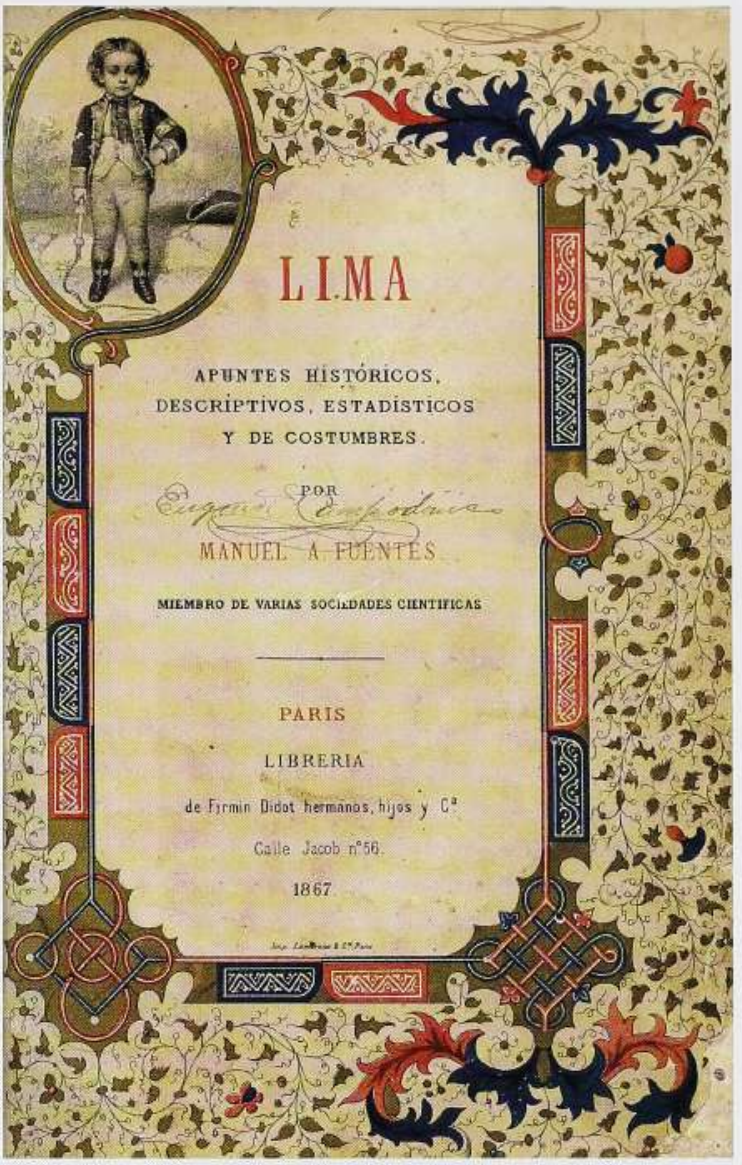

Figura 4 pital. A mediados del siglo XIX el Perú se convirtió una vez más en la generosa y misteriosa tierra que proveía las materias primas que alimentaba y enriquecía a los países industriales. Durante la Conquista española fue la fiebre del oro; la quina contra la fiebre amarilla y la peste negra; la papa alimentó a los irlandeses; ahora era el guano que revitalizaba la tierra agotada de Europa. Había un interés profundo y MAF reescribió su Estadistica de Lima y su Guía del Viagero ${ }^{9}$ (sic) para convertirla en útil e ilustrada guía para conocernos mejor. Fig.4

Manuel Atanasio Fuentes (Lima, 1820 - Barranco, 1889), apodado "El Murciélago", fue un conservador muy influyente en la joven república peruana. Se desempeñó como abogado, catedrático de medicina legal, director de estadística, decano del Colegio de Abogados de Lima y fiscal ante la Corte Suprema, lo que no le impidió ser un destacado periodista que cultivó la sátira política. Escribió laceradas críticas en fugaces periódicos como el Busca Pique, El Heraldo, El Mercurio, la Broma. El murciélago fue escrito íntegramente por nuestro autor, y así se ganó por derecho propio ese mismo sobrenombre. Fig.5

9 Estadistica general de Lima fue publicada en 1858 y la segunda edición fue impresa en París. Tipografia de Ad Lainé et J. Havard. 19 Calle de los Santos Padres. 1866. La Guia del Viajero fue publicada en Lima, 1860. 


\section{Las fuentes de Fuentes}

Para ilustrar su guía, MAF contó con los servicios de los dos estudios fotográficos franceses más exitosos de Lima: el de E. Maunoury, corresponsal de la Casa Nadar de París, y el de los Courret Hermanos. Sobre ellos escribe:

Entre las industrias modernas que más perfección han alcanzado en Lima debe contarse la Fotografía. Sin riesgo de equivocarse puede decirse que se hacen alli tan buenas como en el país más adelantado. Sirve de poderoso auxiliar para esta perfección, el cielo siempre claro y el esplendente sol que ostentan los paises tropicales.

Los gravados (sic) y litografias que adornan esta obra son obras de fotografias salidas de los talleres de los inteligentes artistas Maunoury y Courret Hermanos. ${ }^{10}$

Este texto, publicado en el mismo libro sobre Lima, nos da una clara pista sobre el método utilizado por MAF para la elaboración de los grabados del libro. (Fig.6) Sin embargo,

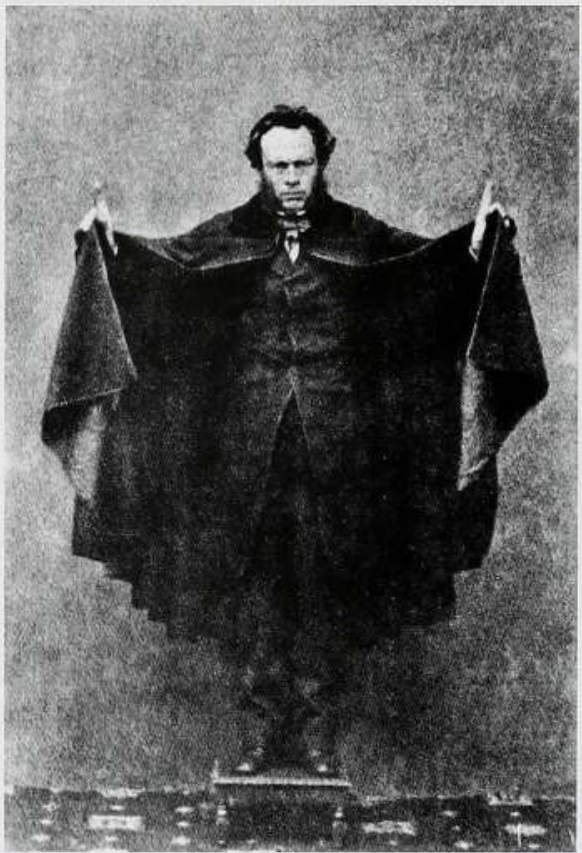

Figura 5. MAFuentes. Autorretrato GT, 1979. no todas las fotografias fueron directas, es decir, muchas fueron reproducciones de otros grabados o acuarelas. Vemos motivos trabajados antes por Bonnafé en litografias, escenas costumbristas de Pancho Fierro y otros artistas populares de la época. De esto da cuenta un extraordinario álbum de tarjetas de visita de la colección de Roberto Fantozzi, publicado en el importante libro del MALI, La recuperación de la memoria. ${ }^{11}$

\section{Los 222 grabados}

El libro de Fuentes está ilustrado con 152 xilografias (grabados en madera) y 70 litografias. La diferencia entre las xilografias y las litografías es la calidad en el detalle. Mientras la técnica del grabado en madera consiste en quitar, con un instrumento muy cortante, todas las partes de la madera que el dibujante no haya cubierto con sus dibujos, el grabador debe seguir línea por línea el dibujo del artista ahuecando los blancos y respetando lo dibujado. Los instrumentos más comunes son los buriles, puntas, agujas, escoplos, gubias, mazo y raspaderas o rascadores $^{12}$. El resultado es una imagen en blanco y negro. La litografía en cambio es un dibujo con lápiz graso sobre una piedra calcárea que al entintarse solo captará la línea del lápiz y al final tendrá más gamas de grises. Algunos paisajes en el libro han tenido además del negro, un color de fondo.

10 Manuel Atanasio Fuentes. Lima, apuntes historicos, descriptivos, estadisticos y de costumbres. Librería de Firmin Didot hermanos, hijos y Co. París 1867. Pag. 67.

11 Natalia Majluf, LE Wuffarden. La recuperación de la memoria, el primer siglo de la fotografía en el Perú (1842-1942). Museo de Arte de Lima / Fundación Telefónica. 2001. Pag. 69.

12 J. Duplessis. Las maravillas del grabado. Libreria Hachette y Ga. 79 Boulevard Saint Germain, Paris, 1873. Traducido por Florencio Janer. p.358 

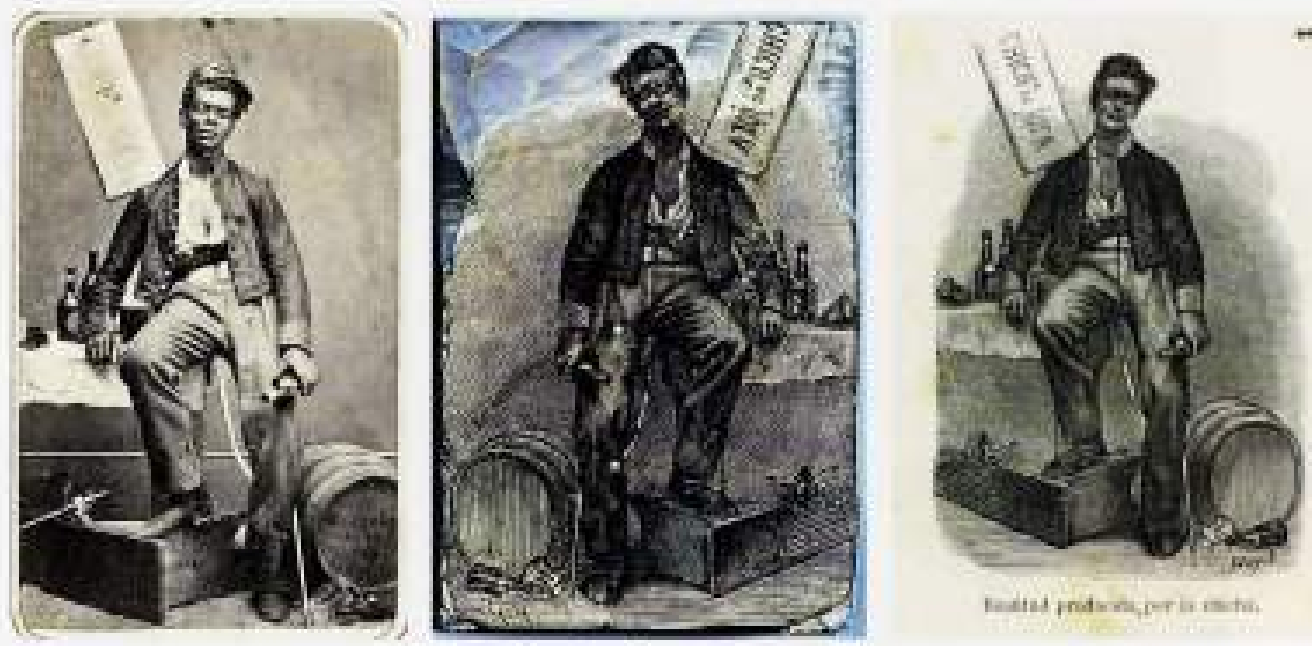

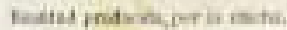

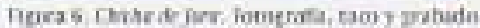

Los grabados en madera (xälografias) colocados en las mismas cajas se imprimieron com los texros: las litografias, en cambio, han sido impresas por separado en el omverses solamente y en un papel diferente, mis grueso y de mejor calidad, El tiempo har conservado ef hlanco de las litografias, mientras el resto del libro ha virado hacia un color más antarillento.

Las fotos que emió MAF a Paris fuercan hechas par el metodo del coloctión humedo!, de vigencia aproximadamente entre 1855 a 1890 , cuando el rollo de film de George Fastman [Kodak] con su lema: "usted apriete el dispasador, nosotrus hacemos el resto" domirró ef negocio fotografico hasta la presente era digital. Con el colodions himedo aparoció el formato de la popular tarjeta de visita o cnrte de wisite, imvento que hizo que la fotografial fuese un negocio lucrativo't. luego surgieron otros formatos exitogos como ef tamano

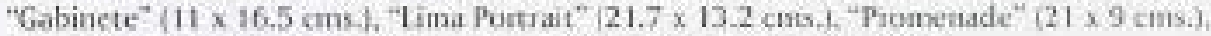
"Imperial" $\{18 \times 24 \mathrm{cms}$, of el pequens "Migaon" (77,7 × 4 cms.). Fig.?

日 estudioso Keith McElroy gran investigadkr de la fotografia peruana del siglo XIX, ya haba identificado algenas fotografías de Courrety Maunoary en los grabados de la Lima de MAr'" Incluso liega a comparar la tarjeta de visita de fourre Hermanos de fos cehidare: con el grabado firmado por Jules Jean M.J. Hayot en el libro de MAF, y werifica que ambes tienen la misana escala: $0.07 \times 0.06$. Hemos compobado que la imayoria de las xilogrnfias son sacadas de tarjetas de visitar y, por otro lado, las fiografias del formato de Gabibete.

Efectinumente la goima de los editores peruanos era comprar o maxdar hacer los tacos o ma* trices en Furopa para usarlos en Peru y luego Aquilarlasa oftos impresones en Lima. Asi venos

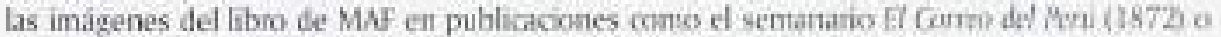
impresos eti los laros de Carlos Prince sabre Lime Antigiva: ios Tipes de Antanio (Lima, 1890)

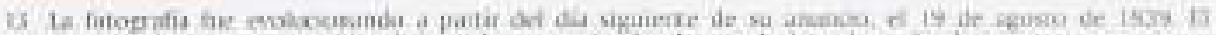

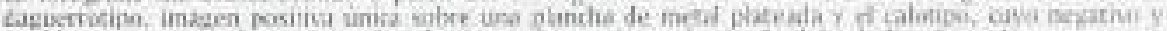

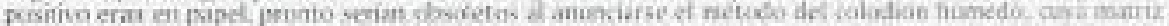

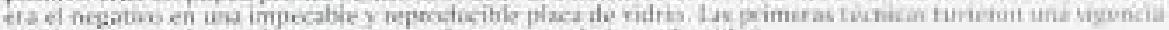

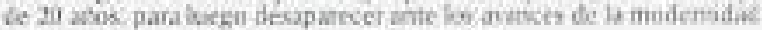

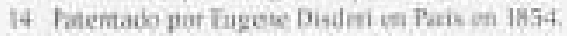

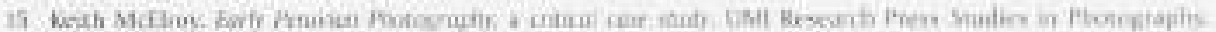
Michean, 1455192 (3) 


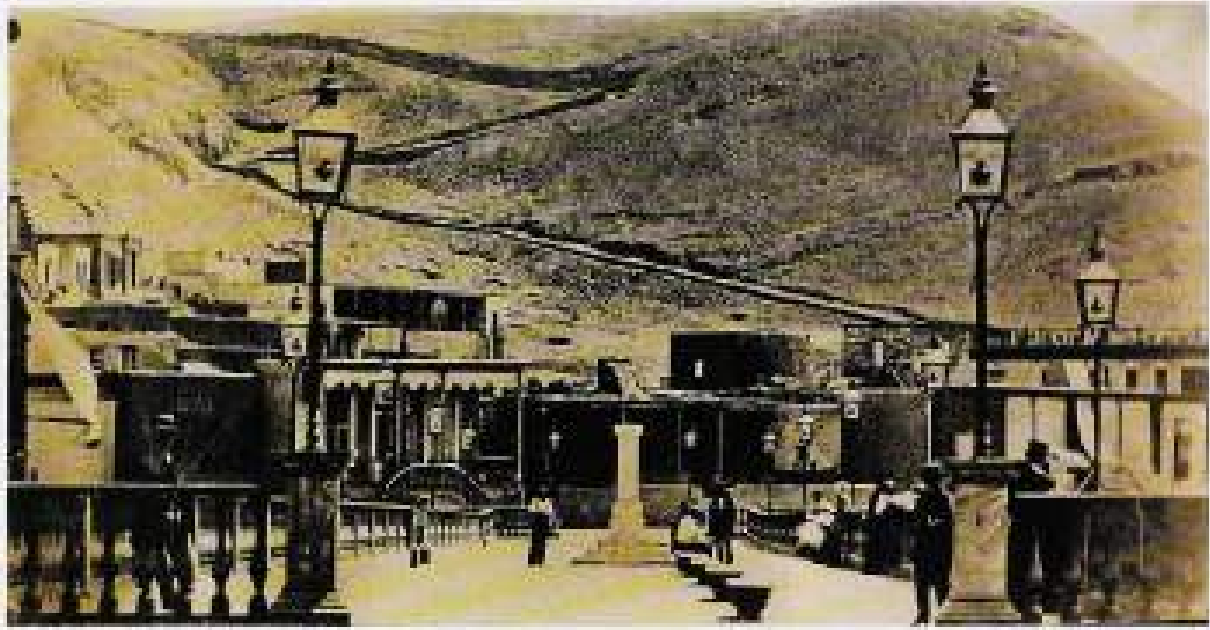

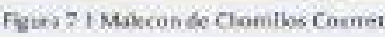

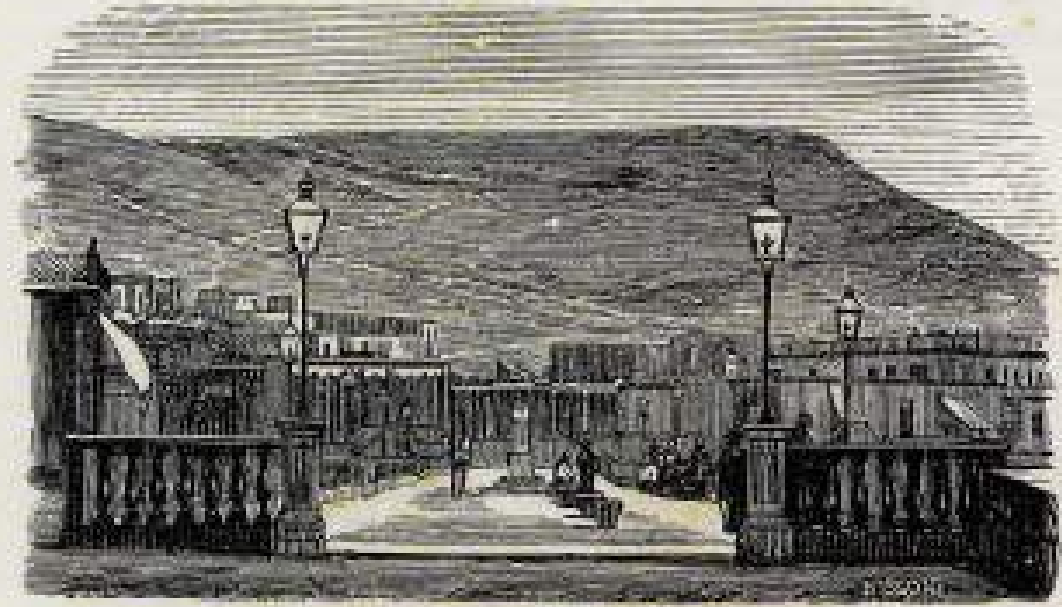

Vista del malecón de Chorrillos.

Fours 72 kakcos de Counifos

\section{$\operatorname{Los} 29$ tacos}

Las viejas matrices reencontradas pertenecieron a un antiguo colecciontista, el doctor José Luis Vastaz. fallecido hace un par de anos. Su viuda, cansada de la cantidad de objetos atesorados por su esposo, optó por llamar a un armigo comun", quicr habria compartido con el doctor su pasión por los huacos y las pinturas cusquenas. La llamada fue escueta y term:nante: "Tengo una caja con unos cachivaches que woy a botar: si los quateres debes recoger. los de inmediato". Apurando ef paso el amigo se encontro con una caja de cartón lfena de

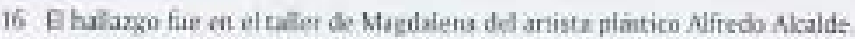




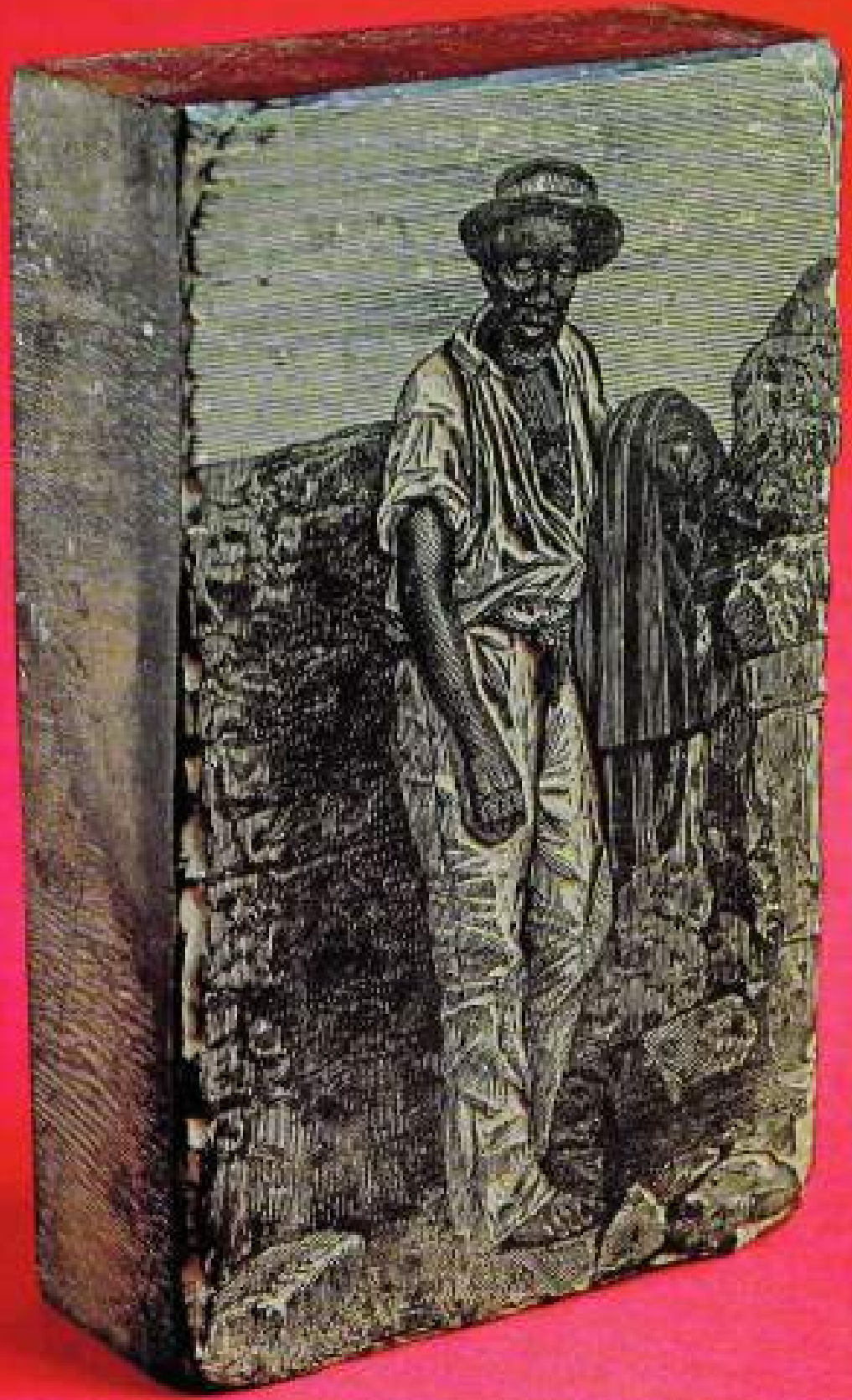

Fiqamen 


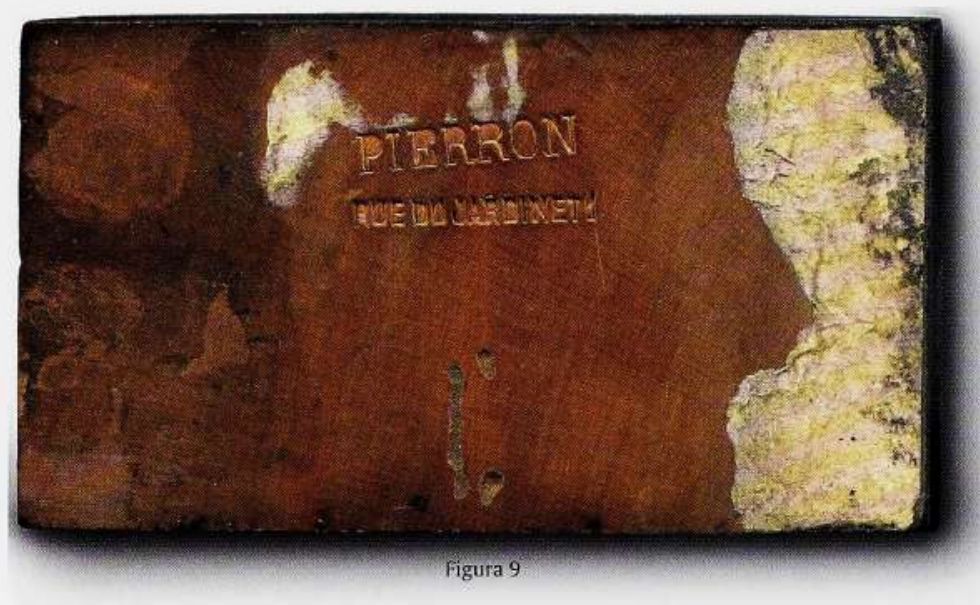

bloques que reconoció como xilografías pero sin saber mucho al respecto. Los bloques se encontraban muy sucios, como si hubieran sobrevivido un huayco, con un fuerte olor a humedad y una fina capa de barro seco encima. Algunos estaban ataca-

dos por la polilla, pero la mayoría se había conservado en buen estado.

A finales del 2012 visité su taller, donde tiene desplegada una colección bastante ecléctica: máscaras, huacos y variados objetos, cosas muy bellas. En un viejo librero vi cinco o seis de estos tacos. Estos tenían lo socavado un color blanquecino por lo que se percibía con claridad la imagen grabada, bastante contrastada. Enseño Historia de la Fotografía en el Centro de la Imagen y en las clases uso el libro de MAF, para demostrar cómo se grababa a partir de fotografias cuando era tecnológicamente imposible imprimirlas. Reconocí al instante los tacos y se lo dije. Me enseñó el resto, que conservaba en la vieja caja de cartón, y la emoción de este hallazgo no pude sino compartirla. Le conté lo que sabía de ellos, le pasé las imágenes del libro de MAF y de El Correo del Perí y de lo raros que eran. Para finales del verano del 2013 hicimos una serie de trueques y pude obtener 37 bloques entre las que se encuentran 29 que pertenecen a la serie usada en el famoso libro de MAF.

\section{Los grabadores}

Los tamaños de los tacos varían ya que no hay dos bloques de madera similares. Los más grandes tienen, por su lado más largo, hasta $8.8 \mathrm{cms}$; por el lado más corto, $4.6 \mathrm{cms}$. El grosor de todos es el mismo: $2.3 \mathrm{cms}$. Algunos tienen aún varias capas de papel pegado en el reverso, los demás tenían vestigios de tal presencia: era para darles tal vez algo de amortiguación, como colchón y para mitigar la presión de la imprenta. Fig.8

Acerca de los artistas que hicieron los grabados debemos diferenciar a los dibujantes de los buriladores, que en muchos casos son personas distintas. En los tacos encontrados vemos algunas firmas. Fuentes fue un editor muy puntilloso e incluyó en el índice varios anexos, entre los cuales es pertinente mencionar el de grabadores e impresores. Los artistas responsables de las xilografias son: Adreux, Albert E. Bertrand, Bisson, J. Cowland y Jules Jean Huyot. A diferencia de las litografias, que llevan la firma del litógrafo y del impresor en la misma lámina, muy pocas xilografías llevan la firma de su autor.

Sobre la manufactura de los bloques en sí podemos decir que ocho de estos bloques o tacos de madera tienen en el reverso un sello francés en bajo relieve: Pierron / rue du jardinet 1. Debajo de algunas litografias del libro de MAF aparece el nombre y la dirección de un impresor vecino: Imp. Godard, rue du jardinet 12, Paris. En una búsqueda por Internet descubrí que Pierron es una prestigiosa casa de grabado que le hizo servicios al gran artista francés Honoré Daumier. Pero este dato solo podía confirmar mi emoción anterior. Fig.9 


\section{BEBUOKRARIA}

\section{Burterfieldi, Koger}

Acrore in dhe popirn. Anetican Heralage fune 1962, Wolume XIII, Xumber 4, P.12.

\section{Ei Correo det Reni}

Colcuciunes del ENP/ IRMMP. Del 16 de verionbie de 1871 al 19 de mayci de 1878.

\section{Fuentes. Manod Aranasio}

C.mo, Lsyersaes, tastoricuessialistiyuas.

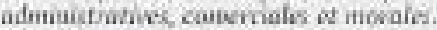
Librcria de FuminDidat hetnanas, hijos y Co. Paris 1866 s. BNP

cona, ar cleicher of the caputal of

Pror. Hisurkai, slalisciral. Liboria de FirminDidot hermanas. hijos y Co. Paris 1866 BNF

Cwa. Apmes Hstoricas Descriptios. Estadistions y de Carumbres. Libreria de Firmindidox hermanks, hipos y Co. París 1862.

Lina Aputer Fistonms. Deseriptavs. Estaubstions jo de Coitumbivs, Abreria de FirminDidex hermanos, hipos y Co. Faris 1867 . Foodo del Libeo - Banco industrial del Peru, 1985,

Eatadistica Ceneral de Lima, Paris 186\%. BNP

Alefozes tel Morcleinge. Pari5. 1866, BNP. 3 Tomos, 17 caricaturas pisliticas a toda pśgise y hietos fanimaks personajes?.

\section{Gegurevich Regal. Juan}

levicio del Fotaperiodismo en et Rete. Separate def Primer Congreso Intersacional de Fuyoperiodismo. Exicey Memoria Poatificia thiversidad Gatolia del Feri. Lima 18 de mayo de 2004,8 PP.

\section{Hogarth. Paul}

The ertist as reporter, A Studio Vistay Reinhoild Art Paperback. London, 1967.

\section{Hutchinson. Thomas}

Jive werers in Pru with explonctions of its anticaritio. Wol. 2. Sampson lowk Co. Londres, 1873 . Solo he revissdo el Tomo 2 de mi propiedad.

\section{I.acano. Richant y George Russell} Eyrustress, 1.50 years of pivotocesmentsm. Time. Insis Second editica, 1995.

\section{Logez Martinex, Héctor}

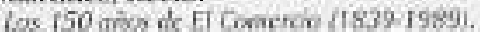
HComerio, 1999.
Mag̣iuf, Natalia y Luis E. Wutfarden La rccuperacion fe fo nemorit, ef prater sugh de in fotugnafio es of Perv 12842 19427. MALI Telefonoca, 2001.

\section{McElrow, Keith}

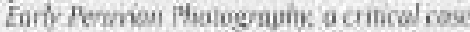
studr. UMI Ressearch Press Studies in Phorography, Midkigan, 1965.192 pp

Malla Batres, Carlas (Edicor)

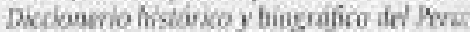
siehs XV.XX. bima 1986. 9 Tomos.

Penaherrera Suachez, Llan ta Fotugrdia en el Peril, apuntes pard una hiseria do la foungrafía es el Peru 1842-19191. Revisfo dei Archwo Generaide a Naxim. Segunda épocs $N^{2} 7$. 5

La totografia en ol Peru. Sepurover Serie A. doc No 9.1 Colocuie Peraano de Fotografia, Lniversidad de Lima Felafacs-forsytec - Hanco de Credito 6. 7 y 8 de Noviembre de $1989.10 \mathrm{pp}$. In docnumento bistorico: Ln Futografor en ef thri 1 1895-1979). Jesis para optar el grado de Bactialler ea Historia. Pontitica Unoworsidad Católica del Perù, Prograna fe letras y Ciencias Humanas, Setiembre. 1983.

Prince, Carlos

Cono Arigan, 1590. Ediuǵn de Carlos Colama Precari. Lima 1992

\section{Taure del Pino. Nlberto} Enciclosedio ilistrodia det Pera. Lima, Persa. 1987

\section{Thoondike, Guillermo}

Altorrerome Feri f850-1500

Promoimuest.tima 1979.Po 164.

Varela, Héctor if

Revatiolion de limas, resecha de los. acontecimentes de juilo. Ilustrada con grabadas hechos expresamente pard esta publicacioia y acompaniade de un juicio sobre las acontecimientes por Eimilio Cestelar, Imprenes HispankAmericana de Rauge. Dinon y Frestie Calke du Four Saint-Germaina, 43. Paris. $1872.110 \mathrm{pp}$

HAmericans, pernodicy llus.rado. Redacción y adminissracon, 17 roed'Aumale. Paris, segenda semestre. 1872 